\title{
The Design and Implementation of Colleges Sports Teaching Management System ZHONG Fangfang ${ }^{1, a}$, WEI Yi ${ }^{2}$ \\ 1,2 jiangxi college of foreign study,NanChang,330099 China \\ a ZhongFangFang1028@yeah.net
}

Keywords: Management System, Sports Teaching, Information Technology. B/S Architecture

\begin{abstract}
With the continuous development of sports information, information technology to fundamentally change the mode of sports management and system, the impact and influence on sports management, traditional sports management concept, organization structure, management method is greatly challenges, such as sports management. Information technology application throughout the whole process of sports management, sports management requirements of implement and perfect the application of information technology, information technology and sports management both promote each other, promote each other. In the process of information technology to interact with sports management, sports management information system is a hotspot of research on sports information related, also is the important content of informatization construction. Specific implementation and application of sports management information system process, it is sports management regularization of specific business process.
\end{abstract}

\section{Introduction}

With the continuous development of society and the progress of science and technology, the management efficiency of higher education has been greatly improved, especially with the scale enlargement of lead to school after enrollment expansion of colleges and universities, to enhance the efficiency of management for the daily operation of colleges and universities has important practical significance. Sports, as one of the important compulsory project in higher education, especially the change of national sports system, the requirements of college sports management is improved remarkably [1]. Because the institutions of higher learning in the subject has the comparative advantage and in the crossover study presents a kind of trend, are brought in institutions of higher learning sports management potential huge room to improve. At the same time, in the ascension space at the same time, also give the corresponding sports management department has brought great pressure. Therefore, how to design and develop effective management systems become higher school sports management department needs to solve the realistic subject [2].

Through the development of sports management system can make colleges and universities sports teaching, thoroughly efficient and informatization and standardization management work, and then make colleges and universities in sports management work efficiency greatly by the bureau. The purpose of this study is to improve the efficiency of sports management, through the design and development of the sports management system, can give congratulation state college sports office staff to provide an efficient, standardized management process, thus is advantageous to the staff sports management functions and goals. Adopts B/S structure to increase the extensibility of the system and maintenance of sexual function. Compared to the traditional software development technology, the sports management system is designed in this paper can effectively control system of the characteristics of the complexity and variability. With the development of the network, this system will be widely used.

\section{Major related technology of the system}

$\mathrm{B} / \mathrm{S}$ architecture (Browser/Server) is one of the WEB after the rise of the network structure model, a WEB Browser is one of the main client application software. This model unifies the client, will be 
the core of the system function realization part focus on the server, simplify the development, maintenance and use of the system. The client as long as the installation of a browser, like Netscape Navigator or Internet Explorer, Server install Oracle, Sybase, Informix or SQL Server database. Browser data through the Web Server and database interactions, thus greatly simplifies the client computer load, reduce the cost of system maintenance and upgrade and workload, and reduce the overall cost of users. The system diagram as shown in figure 1 [3]. B / S mode application system is a thin client, the client uses a browser software, hardware configuration do not ask, easy to manage and maintain the systems, software development, upgrades and maintenance on the server side, reducing development and maintenance work the system does not require the development of client software, web browser software can be downloaded for free from the Internet, free upgrades, system protection business investment, B / S mode uses the standard TCP / IP, HTTP protocol, can be combined with the company's existing network. Also has good scalability. So B/s mode with its easy to use, easy to maintain, high degree of information sharing are gradually replacing C/S mode [4].

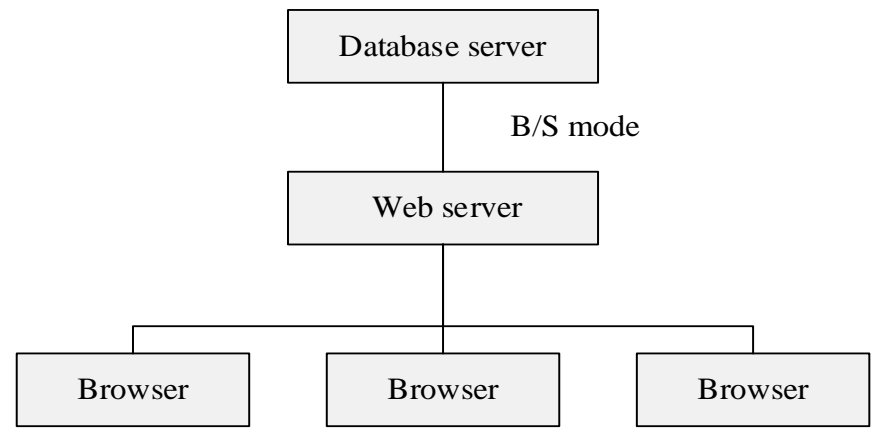

Figure 1. System structure of B/S

$\mathrm{B} / \mathrm{S}$ does not like the C/S mode to install a different client applications on different client. Second, it simplifies system development and maintenance. System developers do not need to for different levels of user application design and development, different customers, just put all the functions implemented on the Web server, and different functions to set permissions for each user group. Individual users within the scope of the authority to call a different HTTP request handler on the Web server to complete or modify the data query [5]. Again, it allows users to operate more easily.

\section{Function analysis of colleges' sports teaching management system}

In spite of the software in the process of the stages of feasibility study and preliminary design has been briefed on the user's requirements, but many details still needs to be done in software requirements analysis phase, therefore, the requirements analysis phase is to perfect the function of the system. Demand analysis of the task is clear, accurate and specific for the target system, the complete requirements, he whatever system to complete the function, just clear what needs to be done function. Figure 2 is the sports management system function of the overall structure, department altogether is divided into five parts, respectively for the user management, sports competitions, fitness testing management, physical education and sports equipment management.

Each plate consists of 2-3 is the module to realize the corresponding function, to ensure that the sports management system to normal operation. Among them, the user management is mainly in relation to the daily management of the users of the system. Sports competitions held management system is mainly aimed at sporting events, the system can carry on the effective management of events, and at the end of the game and the achievements of the athletes of management; Physical fitness test management is mainly aimed at the students' physical fitness testing, for master student's physical condition, the plate is mainly including test items, test scores, and to participate in the test registration personnel information management; Sports teaching management is to manage the daily sports this course for college function plate, mainly including sports curriculum management and performance management of two parts; Sports equipment management is a target in the competition 
or learning a new sport, the relevant person in charge of by the sports equipment management department to borrow and the department of college have equipment number, name and other information management, mainly including equipment use of management and equipment management information of two plates.

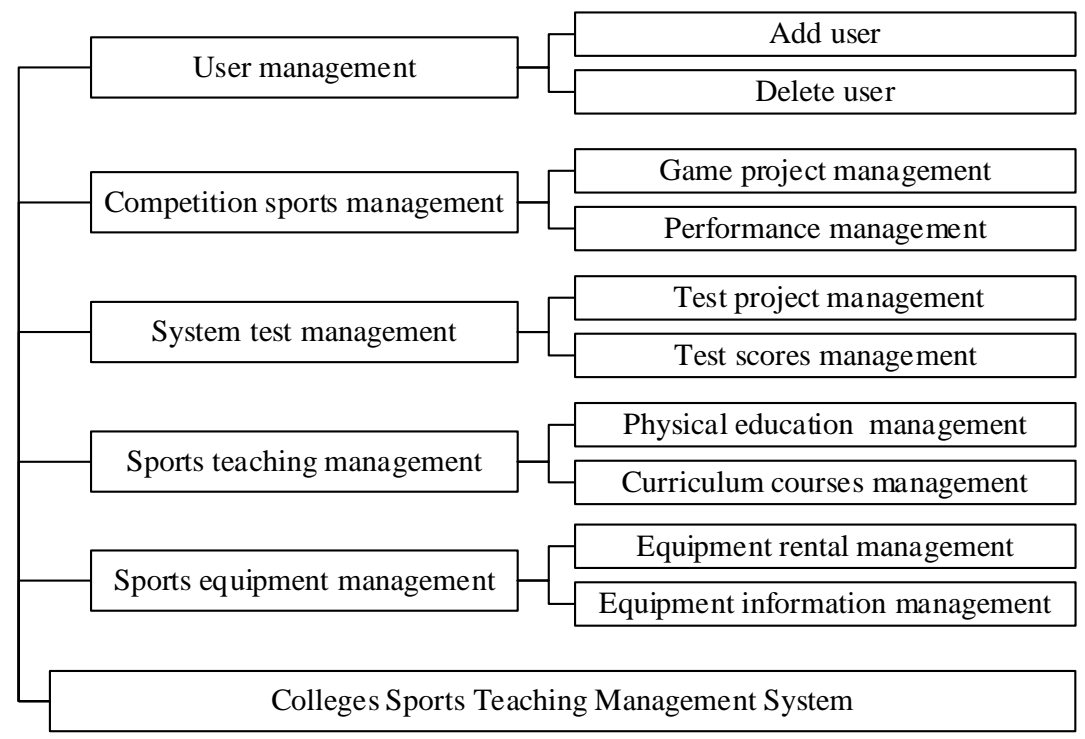

Figure 2. Function structure of colleges’ sports teaching management system

\section{Overall design of colleges’ sports teaching management system}

Sports teaching system uses a modular design method for the center with the data connection between modules, the system according to the functions are divided into different modules, modules and segment for each module, top-down functional decomposition. The whole system based on data processing center, at the same time, considering the cohesion and coupling between modules, the database for the data transmission between system modules of data center, thus raising the independence between modules, enhance the scalability of the system. The system application architecture construction scheme is refers to the process in the whole system. The application architecture of this system is divided into three layers, namely the presentation layer, business layer and application support access layer. Three layers between closely linked, with the interaction between the users. The system application architecture is shown in figure 3.

Presentation layer. Presentation refers to receiving/display user information interactive interface, users can take advantage of the layer for data input and display. Considering the user use the convenience of the system, this paper will be the solution to implement the system based on web pages of the presentation layer. By the application layer, can realize the user access, login, authentication, information release, and other functions.

Application layer. Application main function is to develop the business rules and business process implementation. Three layer application architecture design, allows the user to avoid the directly interact with the database, business rules, data access, and the check of legitimacy has business logic layer to complete the work, the user interactions with the data from the business logic layer, thus increasing the portability and scalability of the program. The application layer can be implemented teaching management system of information release, teacher management, student management, online classes, system management, and other functions, and realize the interact with the database.

Application support layer. Application support layer integration of various resources, at the same time for the application layer provides a wide range of skills. Application support layer can implement security certification, public resource configuration management, data exchange service and platform access interface. Through this layer is to access the database at the same time, to update the database, modify, delete, and query operations. Application support layer to provide data 
support to the business layer, solely responsible for the data maintenance and modification, to improve the efficiency of data processing.

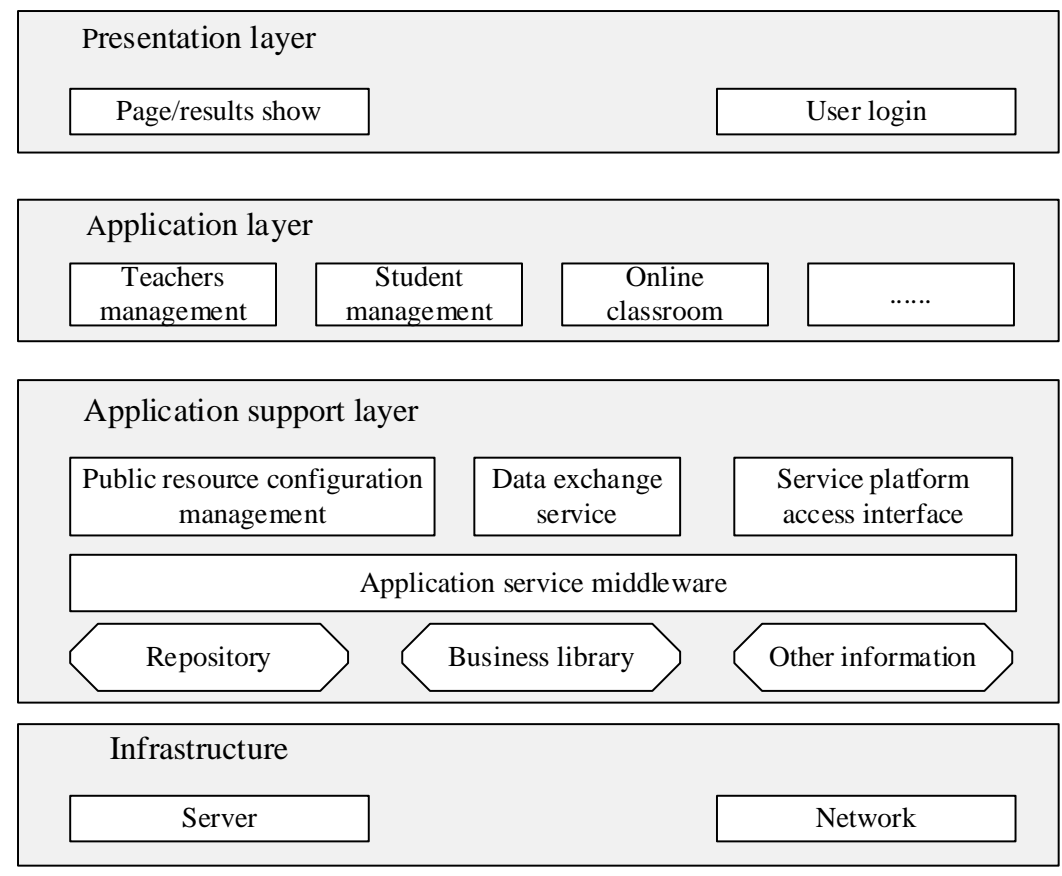

Figure 3. Overall structure of colleges’ sports teaching management system

\section{Conclusion}

With the popularization of computer technology, computer technology has been involved in all walks of life in China, and was a great achievement. So, the computer technology in college physical education has been popular, under the present situation of student populations, the complexity of the physical education teaching management also corresponding increase. Sports teaching has the following characteristics: large amount of information, information processing ability, save time, etc. So, must choose reliable, efficient and stable computer information processing platform. Based on the teaching mode under the background of innovation and change constantly emerging, based on B/S structure of sports teaching management system analysis and design, the purpose is to build a suitable teaching management system, the system can not only bring the teacher teaching on convenience, also can improve the learning efficiency of students, to further promote learning resources sharing.

\section{References}

[1] H. Fan: Journal of Convergence Information Technology, Vol. 7 (2012) No.15, p.463.

[2] R. Halverson, and A. Smith: Journal of Computing in Teacher Education, Vol. 26 (2009) No.2, p.49.

[3] L. Masteralexis, C. Barr, and M. HumsPrinciples and practice of sport management, Jones \& Bartlett Publishers, 2011.

[4] H. Geng, C. Wu: Journal of Convergence Information Technology, Vol. 7 (2012) No.14, p.368.

[5] L.A. Burke, and B. Rau: Academy of Management Learning \& Education, Vol. 9 (2010) No.1, p.132. 